\title{
吸放湿におよぼす吸着熱の影響
}

正会員前田敏男* 同 ○松本衛**

§!。序 従来，吸放湿を佮えた湿気計算では，吸着 熱は無視し得るとして取扱われてきた。吸着熱を無視す ることの可否を知るために，吸着熱を考慮した基礎式 を用い，吸放湿性の大きい半硬質木繊維板について室温 一定の場合の吸湿水分量预よび板内温度の時間経過を計 算し，吸着熱を無視した場合と比較した。

§2. 基礎式') 材料内空隚の絶対湿度を $X\left(\mathrm{~kg} / \mathrm{kg}^{\prime}\right)$ とする。 $X=X_{x}+X_{0}$ とおくと

$$
\begin{aligned}
& \left(c^{\prime} \gamma^{\prime}+\kappa\right) \frac{\partial X_{x}}{\partial t}=\lambda^{\prime} \frac{\partial^{2} X_{x}}{\partial x^{2}} \\
& \left.\begin{array}{c}
x=0 \text { で } \lambda^{\prime} \frac{\partial X_{x}}{\partial x}=\alpha^{\prime}\left(X_{x}-X_{r}\right), x=l \text { で } \\
\frac{\partial X_{x}}{\partial x}=0
\end{array}\right\} \\
& \left(c^{\prime} \gamma^{\prime}+\kappa\right) \frac{\partial X_{\theta}}{\partial t}=\lambda^{\prime} \frac{\partial^{2} X_{0}}{\partial x^{2}}+\nu \frac{\partial \theta}{\partial t} \\
& (c r+r \nu) \frac{\partial \theta}{\partial t}=\lambda \frac{\partial^{2} \theta}{\partial x^{2}}+r_{*} \kappa \frac{\partial X_{\theta}}{\partial t}+r \kappa \frac{\partial X_{x}}{\partial t} \\
& x=0 \text { で } \lambda^{\prime} \frac{\partial X_{\theta}}{\partial x}=\alpha^{\prime} X_{\theta} ; \lambda \frac{\partial \theta}{\partial x}=\alpha \theta \\
& x=l \text { で } \frac{\partial X_{\theta}}{\partial x}=0 ; \frac{\partial \theta}{\partial x}=0
\end{aligned}
$$

記号: $\theta=$ 材料内の温度 $\left({ }^{\circ} \mathrm{C}\right), \lambda^{\prime}=$ 湿気伝樽摔 $(\mathrm{kg} / \mathrm{mh}(\mathrm{kg} /$

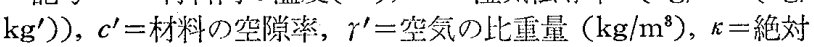
湿度 $1\left(\mathrm{~kg} / \mathrm{kg}^{\prime}\right)$ 上昇飞対与る吸湿量 $\left(\mathrm{kg} / \mathrm{m}^{8}(\mathrm{~kg} / \mathrm{kg}), \nu=\right.$ 温度 $1^{\circ} \mathrm{C}$ の上昇に対方方放湿量 $\left(\mathrm{kg} / \mathrm{m}^{3 \circ} \mathrm{C}\right.$ )，c=材料の比熱 ( $\mathrm{kcal} /$ $\left.\mathrm{kg}^{\circ} \mathrm{C}\right), \gamma=$ 材料の比重量 $\left(\mathrm{kg} / \mathrm{m}^{3}\right), r=$ 吸滔熱 $(\mathrm{kcal} / \mathrm{kg}), \alpha^{\prime}=$ 湿 気伝達率 $\left(\mathrm{kg} / \mathrm{m}^{2} \mathrm{~h}\left(\mathrm{~kg} / \mathrm{kg}^{\prime}\right), \alpha=\right.$ 熱伝達率 $\left.\left(\mathrm{kcal} / \mathrm{m}^{2} \mathrm{~h}^{\circ} \mathrm{C}\right)\right), X_{r}$ 二室の絶刘湿度 $\left(\mathrm{kg} / \mathrm{kg}^{\prime}\right), \theta_{r}=$ 室温 $\left({ }^{\circ} \mathrm{C}\right)$

\$3. 計算法 (1)(2)式莸数值解法により解を求好 た。(1)式は概知の解法 ${ }^{2}$ ，(2) 式は以下の循環式によ る。板を $\Delta x$ に分㓶し, 任意の分割線上の絶対湿度, 温 度を $X_{0(0)}, \theta_{(0)}$ としその前後のものをそれぞれ $X_{\theta(T)}$ ， $X_{\theta(1)}, \theta_{(T)}, \theta_{(1)}$ とし, $\Delta t$ 時閒後の分割線上の值を $X_{\theta(0 \Delta t)}, \theta_{(0 \Delta t)}$ とする。 $\partial X_{\theta} / \partial t を\left(X_{\theta(0 \Delta t)}-X_{\theta(0)} / \Delta t\right.$, $\partial^{2} X_{\theta} / \partial x^{2}$ を $\left(X_{\theta(T)}+X_{\theta(1)}-2 X_{\theta(0)}\right) /(\Delta x)^{2}$ と拈皇, $\theta$ についても同じようにして $(2)$ 式に代入，整理すると

$$
\begin{aligned}
& X_{\theta(0 \Delta t)}=\frac{1}{1-w b}\left\{p ^ { \prime } \left[X_{\theta(T)}+X_{\theta(1)}+\left(\frac{1-w b}{p^{\prime}}-2\right)\right.\right. \\
& \left.X_{\theta(0)}\right]+b p\left[\theta_{(\Upsilon)}+\theta_{(1)}-2 \theta_{(0)}\right]+w b^{\prime}\left[X_{x(0 \Delta t)}\right. \\
& \left.\left.-X_{x(0)}\right]\right\} \\
& \theta_{(0 \Delta t)}=\frac{1}{1-w b}\left\{w p^{\prime}\left[X_{\theta(\mathcal{T})}+X_{\theta(\mathrm{T})}-2 X_{0(0)}\right]\right. \\
& +p\left[\theta_{(1)}+\theta_{(1)}+\left(\frac{1-w b}{p}-2\right) \theta_{(0)}\right]+w\left[X_{x(0 \Delta t)}\right. \\
& \left.\left.-X_{(0)}\right]\right\}
\end{aligned}
$$

$\Delta x \theta_{(0)}$ を代入したもの。 $p^{\prime}=a^{\prime}\left\{\Delta t /(\Delta x)^{2}\right\}, a^{\prime}=\lambda^{\prime} /\left(c^{\prime} \gamma^{\prime}\right.$ $+\kappa), p=a\left\{\Delta t /(\Delta x)^{2}\right\}, a=\lambda /(c r+r \nu), b=\nu /\left(c^{\prime} \gamma^{\prime}+\kappa\right)$, $w=r \kappa /(c r+r \nu), h^{\prime}=\alpha^{\prime} / \lambda^{\prime}, h=\alpha / \lambda$ である。

$(1-w b) / p^{\prime}-2>0, \quad(1-w b) / p-2>0$ (境界では $\{(1$ $\left.-w b) / p^{\prime}-\left(1+h^{\prime} \Delta x\right)\right\}>0,\{(1-w b) / p-(1+h \Delta x)\}>$ 0 にになるよう $\Delta t /(\Delta x)^{2}$ を選んで計算した。

\$4. 計算結果と考察 愿さ $9 \mathrm{~mm} の$ 半硬質緎維板に ついて室の絶対湿度 $X_{r}=1 \times 10^{-3}\left(\mathrm{~kg} / \mathrm{kg}^{\prime}\right), t>0$ で計算 した。 $\kappa=3080, \nu=1.715$ ，(以上平衡含湿率実測值より $20^{\circ} \mathrm{C}, 4 \sim 10 \times 10^{-3} \mathrm{~kg} / \mathrm{kg}^{\prime}$ に括ける平均值） $\lambda^{\prime}=0.0169$, $r=318$ (以上実測) $c^{\prime}=0.788, r^{\prime}=1.205, \lambda=0.10, c=$ $0.44, \alpha^{\prime}=38, \alpha=8, r=606$ である。

$\Delta x=3 \mathrm{~mm}, \Delta t=5.47 \times 10^{-3} \mathrm{~h}$ ，（境界では $5.47 / 2 \times$ $10^{-3} \mathrm{~h}$ ) で計算した。 $X_{x}$ の計算結果（吸着熱無視の場 合)を図一1に， $X_{\theta}, \theta$ を図一 2 に示す。 $\dot{X}_{\theta}, \theta$ の值が $t=0$ 近偣で大きく振動しているがこれ 羔で， $\Delta t$ をこの近傍で小さくとれば防げる。この振

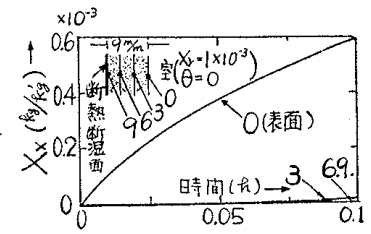

図一1 $X_{x}$ の部算結果

動の振幅は時間がたつと共に 減少しているので，誤差の累 積で計算值が不安定になるこ とはない。計算結果を滑らか な曲線で描いたものを破線で 示与。

板表面の各時刻の吸湿水分 量 $\left(\mathrm{g} / \mathrm{m}^{2} \mathrm{~h}\right)$ の計算結果を図 -3 に示寸。吸着熱老無視す るときわめて大きい誤差が生 じる。吸着熱による温度上昇 泷一 2 (b)のごとくで $0.1 \mathrm{~h}$ 後で約 $0.5^{\circ} \mathrm{C}$ ，この場合通常 の壁体に生じる温度変動に対
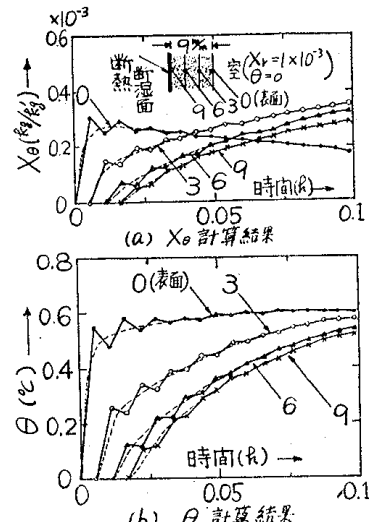

(b) $\theta$ 計莫結果

図一2 $X_{\theta}, 0$ の訪算結果

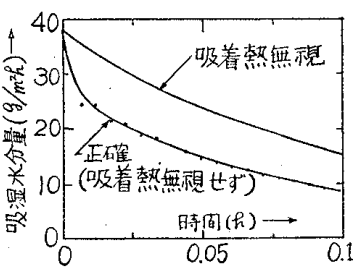

図一3 吸着熱を無視した場 合としない場合の吸湿 水分量の比較

して無視できない。

\section{[文 献]}

（1）前田，吸放湿のある場合の多数空の 湿度計算法 建築

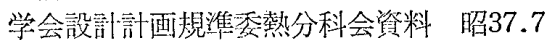

(2) 前田, 建築学大系 8 伝熱学 彰国社 昭 30.7

* 京都大学教授・工博 $* *$ 神戸大学助教授 